\title{
Radiation safety in the cardiac catheterization laboratory: our responsibility to change
}

\author{
${ }^{1}$ Eugenio Picano, ${ }^{2}$ Emanuela Piccaluga, ${ }^{3}$ Renato Padovani, ${ }^{4}$ Claudio Antonio Traino, \\ Maria Grazia Andreassi, ${ }^{5}$ Giulio Guagliumi \\ ${ }^{1}$ CNR, Institute of Clinical Physiology, Pisa, Italy; ${ }^{2}$ Cardiology Unit, Hospital Sacco, Milan, Italy; ${ }^{3}$ Medical Physics \\ Department, University Hospital, Udine, Italy; ${ }^{4}$ Division of Health Physics University Hospital of Pisa, Pisa, Italy; \\ IInterventional Cardiology Unit, Ospedale Papa Giovanni XXIII, Bergamo, Italy
}

Abstract

\begin{abstract}
Medical radiation from $x$-rays and nuclear medicine is the largest manmade source of radiation exposure in Western countries, and accounts for a mean effective dose of 3.0 milliSievert $(\mathrm{mSv})$ per person per year, equivalent to the radiological risk of 150 chest x-rays. Of these, $0.43 \mathrm{mSv}$ come from interventional radiology $(0.20 \mathrm{mSv})$ and interventional cardiology $(0.23 \mathrm{mSv})$. Among adult cardiology patients, fluoroscopically-guided diagnosis and intervention account for $12 \%$ of all radiological examinations performed, and $48 \%$ of their total collective dose. On average, a diagnostic invasive angiogram corresponds to a patient radiation exposure of about $7 \mathrm{mSv}$ (range 2-16), while coronary stenting corresponds to $15 \mathrm{mSv}$ (range 7-57). Progressively higher effective doses are observed for transcutaneous aortic valvuloplasty $(39 \mathrm{mSv}$ ), dilation of total occlusion of coronary arteries ( $81 \mathrm{mSv}$, range 17-194) and endovascular thoraco-abdominal aneurysm repair procedure (76-190 mSv). Most experienced (and most exposed) interventional cardiologists have an exposure per annum of around 5 $\mathrm{mSv}$, two to three times higher than diagnostic radiologists, with a typical cumulative lifetime cumulative exposure around $100 \mathrm{mSv}$ and attributable risk in the order of magnitude of 1 cancer (fatal and non-fatal) per 100 exposed subjects. However, adequate radiation protection training and diligent protection can reduce this radiation exposure by $90 \%$. Attention to radiation protection is one aspect - and not the least important - of good practice of interventional cardiology.
\end{abstract}

Key words cancer, catheterization, radiation, responsibility, sustainability

\section{Introduction}

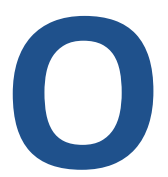

ver the last 20 years, invasive fluoroscopy and interventional cardiology have expanded significantly in the field of diagnostic studies, interventions, and device implantation. The effective dose (ED) to patients in invasive fluoroscopy procedures can range anywhere from 1 to 100 milliSievert ( $\mathrm{mSv}$ ), equivalent to a radiological risk corresponding to 50 to 5000 chest $x$-rays ${ }^{1}$. The occupational exposure of interventional cardiologists can be two to three times higher than that of diagnostic radiologists ${ }^{2,3}$. The increasing use and complexity of interventional cardiology techniques have not been matched by increasing awareness and knowledge by prescribers and practitioners. Most doctors - including invasive cardiologists - grossly underestimate the radiation doses for most commonly requested tests ${ }^{4,5}$. However, this knowledge is crucial for several reasons. First, the dose is proportional to long-term cancer risk, and therefore one must be aware of the dose in order to perform a proper risk-benefit assessment, quintessential for evaluating the appropriateness of any given test or procedure. Second, knowing the dose is necessary in order to apply dose optimization, intended to achieve the desired diagnostic information or therapeutic benefit with the lowest necessary dose. Third, radiation awareness is essential for better protection of interventional cardiologists and staff (technicians and nurses), since simple radioprotection knowledge can reduce occupational exposure by tenfold, making one's professional life longer and healthier. These are three excellent reasons to pursue a policy of radioprotection in the cardiac catheterization $l a b^{6-8}$.

\section{Deterministic and stochastic risks in the cardiac catheterization lab}

There are two main biological effects of radiation: tissue reactions (deterministic effects), which occur when the radiation dose exceeds a specific threshold and become evident days to months after exposure as a predictable change in tissue occurs, and stochastic effects, which relate to the potential for future harm to the tissue and the body, 10 . 
Table 1. Doses of common examinations in the cardiac catheterization lab

\begin{tabular}{|c|c|c|c|}
\hline & Invasive Fluoroscopy & Effective dose (mSv) & Equivalent CXRs \\
\hline \multirow{11}{*}{ 占 } & Diagnostic coronary angiography & $7(2-16)$ & 350 \\
\hline & $\mathrm{PCl}$ & $15(7-57)$ & 750 \\
\hline & Thoracic angiography (pulmonary or aorta) & $5(4-9)$ & 250 \\
\hline & Abdominal angiography or aortography & $12(4-48)$ & 600 \\
\hline & Pelvic vein embolization & $60(44-78)$ & 3000 \\
\hline & TIPS placement & $70(20-180)$ & 3500 \\
\hline & Aortic valvuloplasty & 39 & 1950 \\
\hline & Dilation chronic coronary occlusion & $81(17-194)$ & 4050 \\
\hline & ETAAAR procedure & $76-119$ & $3800-5950$ \\
\hline & Renal angioplasty & 54 & 2700 \\
\hline & Iliac angioplasty & 58 & 2900 \\
\hline \multirow{4}{*}{$\frac{\frac{u}{\underline{\underline{c}}}}{\frac{\mathbf{c}}{\mathrm{u}}}$} & Diagnostic cardiac catheterization & $6.0(0.6-23.2)$ & Age-dependent \\
\hline & Closure of ASD & $2.8(1.8-7.4)$ & Age-dependent \\
\hline & Patent ductus arteriosus occlusion & $7.6(2.1-37)$ & Age-dependent \\
\hline & Balloon valvuloplasty & $8.1(2.9-20)$ & Age-dependent \\
\hline
\end{tabular}

Deterministic (tissue reaction) effects of most concern for patients and operators include skin injuries (reported in patients during long, repeated and complicated interventional procedures). The severity of tissue reactions, rather than probability of occurrence, is proportional to the dose imparted to the tissue. Patient skin injuries may occur when fluoroscopic procedures exceed 20 min using high-contrast fluoroscopy mode, or $60 \mathrm{~min}$ in low-level fluoroscopy. Tissue injury following fluoroscopic guided procedures remains asymptomatic and often goes unrecognized as it occurs weeks after the procedure. They usually occur on the patient's back (where the $x$-rays are delivered) and many severe cases come to light only through litigation ${ }^{11}$. A case is filed in the US courts every 4 to 5 weeks by patients who have suffered such injuries ${ }^{12}$.

The lens is a radiosensitive tissue, and thus cataract formation is the primary ocular complication associated with ionizing radiation exposure for both patients and doctors. Until recently, the dose threshold for radiationinduced lens opacities was considered 2 Sv for a single dose or 5 Sv for fractionated dose. Currently, radiationinduced cataract, previously thought to be deterministic (tissue reaction), is now recognized to be possibly stochastic in nature, occurring at a much lower radiation exposure level than previously thought. Indeed, several epidemiological studies showed an increased incidence of lens opacities at doses below $0.5 \mathrm{~Sv}$. Accordingly, on April 21, 2011 the International Commission on Radiological Protection (ICRP) slashed the earlier dose limit of $150 \mathrm{mSv}$ in a year for the lens of the eye, to the present $20 \mathrm{mSv}$ in a year, averaged over a defined period of 5 years, with no single year exceeding $50 \mathrm{mSv}^{13}$. Eye cataracts, with the radiation-specific type of posterior sub-capsular opacities, can be observed in one-third of staff after 30 years of work - as a consequence of lack of specific protection and too-permissive limits allowed for the current generation of workers up to $2011^{14}$.

The stochastic effect of most concern is a carcinogenic effect (in both exposed patients and doctors). It occurs when the cell is modified by damage to its DNA but remains viable, the harm eventually being expressed through cell proliferation. Ionizing radiation damages DNA molecules either directly (though ionization of the DNA molecule) or indirectly (through generation of free radicals and reactive oxygen species in the surrounding medium). Cancer occur after a latency period of many years. Reducing the risk of cancer is at the core of the radioprotection system for patients and staff ${ }^{15}$.

\section{Radiation doses}

The radiation doses of common invasive fluoroscopy examinations are reported in Table 1 . As a reference dose, a conventional chest radiography (single posteroanterior projection) corresponds to $0.02 \mathrm{mSv}$; a 64-slice coronary CT to 15 mSv (3-32) and a Sestamibi Myocardial Perfusion Scintigraphy to $9.4 \mathrm{mSv}^{1}$.

On the equipment's display, values are usually reported as a dose-area product (DAP) or Kerma-area products (KAP) indicating total energy impacting the patient for a given procedure. As a general rule, ED can be estimated approximately as follows: $\mathrm{ED}(\mathrm{mSv})=\mathrm{DAP}\left(\mathrm{Gy} \times \mathrm{cm}^{2}\right) \times 0.2$ $\left(\mathrm{mSv} / \mathrm{Gy} \mathrm{cm}^{2}\right.$ ). The conversion factor (from DAP to $\mathrm{mSv}$ ) is age-specific, and increases with decreasing age. In adults, the dose in $\mathrm{mSv}=\mathrm{DAP}(\mathrm{Gycm} 2) \times 0.2$. Consequently, DAP quantity represents a relevant dosimetry index, the value of which should be optimized against the diagnostic reference level, which varies for each procedure and can be used as a tool to comply with the ALARA (As Low As Reasonably Achievable) principle ${ }^{1}$.

The many factors modulating the dose in the cardiac cath lab are summarized in Table 2 and can reduce the dose by a factor of 10 to $100^{16-18}$.

\section{Protection of personnel}

Protection of doctors is just as important as the protection of patients. Most experienced (and most exposed) cardiac electrophysiologists have an exposure per annum of around $5 \mathrm{mSv}$, two to three times higher than diagnostic radiologists, with a typical cumulative 
Table 2. Factors modulating doses in the cardiac catheterization laboratory

\begin{tabular}{|l|l|l|l|}
\hline & & Lower doses & Higher doses \\
\hline Operator-dependent & Operator background & Expert & Beginner \\
\hline & Cath lab director & Radiation aware & Not radiation aware \\
\hline & Written records & Includes KAP & Omits KAP \\
\hline & Arterial approach & Transfemoral & Transradial \\
\hline & Pulsed fluoroscopy rate & Low ( $\leq 12.5 \mathrm{fps})$ & High (>12.5 fps) \\
\hline & Patient to intensifier distance & Small & Large \\
\hline & Ventriculography & No & Yes \\
\hline & Cine-duration & Short & Long \\
\hline & Magnified views & Few & Many \\
\hline & Projection & Ant, RAO & Lateral, LAO \\
\hline & Dose audit & Yes & No \\
\hline Patient-dependent & Body habitus & Lean & Obese \\
\hline & Coronary lesion to be dilated & Simple, single & Complex, multiple \\
\hline $\begin{array}{l}\text { Technology- } \\
\text { dependent }\end{array}$ & X-ray system & inspected for QC & Not tested for QC \\
\hline
\end{tabular}

RAO: Right Anterior Oblique projection; LAO: Left Anterior Oblique projection; KAP: Kerma Area Product; QC: quality control

lifetime attributable risk on the order of magnitude of 1 cancer (fatal and non-fatal) per 100 exposed subjects ${ }^{3}$. Operator dose per procedure correlates somewhat with the patient dose, but may be typically 1000 times lower depending upon the shielding employed (one unit of incidence scatter dose for the operator when 1000 units of incidence dose are given to the patient). However, adequate radiation protection training and diligent protection can reduce this radiation exposure by $90 \%{ }^{19}$.

\section{The order of magnitude and risks}

A cumulative ED of $100 \mathrm{mSv}$ may be reached by a patient after four ablation procedures plus two or three CT's, with an extra-risk of cancer of 1 in 100. The same cumulative dose of $100 \mathrm{mSv}$ can be reached by an experienced invasive cardiologist after 30 years of work. This is a „population” risk, and the true individual risk is dictated - as always in medicine - by genetic and environmental factors. For instance, the average dose of $15 \mathrm{mSv}$ confers a risk of one extra-cancer in every 750 exposed 50 -yearold male patients, but the risk is $38 \%$ higher in women, must be multiplied by 4 in children, and is reduced by $50 \%$ in an 80 -year-old man. The risk is higher in presence of some unfavorable polymorphisms of genes involved in DNA repair and in presence of other environmental carcinogens such as smoking ${ }^{20,21}$. The risk can probably be reduced with chemoprotective strategies, for instance with anti-oxidant cocktails ${ }^{22}$, although the cost-benefit assessment of these strategies remains unsettled.

The use of fluoroscopy during invasive fluoroscopy intervention (such as catheter radiofrequency ablation) is likely to result in a small increase in the lifetime risk of a fatal malignancy, and the most likely malignancies will be lung, bone marrow (leukemia) and the breast, the organs exposed to the maximum amount of radiation ${ }^{23}$.

The risk may be acceptable when flanked with a documented or expected benefit, but it is not negligible, and should be spelled out in the informed consent form before the procedure ${ }^{24}$. After the examination, the actual dose delivered should be stored in the patient's and laboratory's records. This simple process will gently force the doctor to learn what he/she should already know, enabling him/her to make more responsible choices $^{25}$.

\section{Novel opportunities in the cardiac cath- eterization laboratory}

The challenges of radioprotection in the cardiac catheterization lab opens exciting new opportunities for the clinician, the clinical scientist, and the pharma and technology industries, in a perspective that will rapidly positively impact on both patients and doctors ${ }^{26}$.

For the clinician, the simple adoption of a radiation history to be included in medical records will modify the current clinical perspective. Cumulative radiation exposure is a recognized risk factor for cancer and probably for atherosclerosis ${ }^{27}$, and a dedicated radiation history should be systematically collected in the medical re$\operatorname{cords}^{28-30}$. The step-up in the quality of this section of the records is linked to the progressive shift from reference dose to truly delivered doses for that patient in the specific examinations. This will increase the quality of the clinical information, serve as feedback for the patient on the quality of care received, and eventually lead the physician and the interventional cardiologist towards a radiation-conscious practice.

For the interventional cardiologist, the possibility of becoming familiar with novel radiation-sparing approaches will open new professional opportunities. For instance, one possible strategy for reducing radiation exposure in the pediatric population is to use X-ray magnetic resonance fusion, with $30 \%$ reduction in contrast dose and radiation dose - albeit with longer anesthesia time ${ }^{31}$.

For the researcher, it is essential to move from the current evidence-poor to an evidence-rich milieu, with data directly linking radiation exposure to cancer and 
Table 3. Radiation in the cath lab: our responsibility to change

\begin{tabular}{|c|c|c|c|}
\hline \multirow{8}{*}{ 占 } & & What we have & What we need \\
\hline & Dominant culture & More (exams) is better & Less (dose) is more \\
\hline & Keep record & Number of test & Dose of each \\
\hline & Radiation history & Absent & Present \\
\hline & Informed consent & Ignored & Spelled-out \\
\hline & Received dose in report & Missing & Mandatory \\
\hline & Dose coding & KAP or DAP & Effective dose (mSv) \\
\hline & Dose & Ignored & Considered \\
\hline \multirow{6}{*}{$\begin{array}{l}\stackrel{\Upsilon}{\circ} \\
\text { 음 } \\
\text { ○ }\end{array}$} & Technology upgrading & More short-term cost & Less long-term risk \\
\hline & Lowering dose & A curiosity for physicist & Preventing cancer \\
\hline & The cancer risk & Theoretical & A professional risk \\
\hline & What can protection do & Reduce work comfort & Allow to live longer \\
\hline & Dose reading & Off-line, months after & On-line, real time \\
\hline & Risk of the staff & Population-based & Personalized \\
\hline \multirow{4}{*}{ 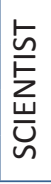 } & Risk estimation & Population-based & Tailored \\
\hline & Epidemiological data on staff & Nuclear plant workers & Cath lab workers \\
\hline & Epidemiological data on pts & Children with CT & CHD patients \\
\hline & Focus on risks & Only Cancer risks & Non-cancer risks \\
\hline
\end{tabular}

CHD: congenital heart disease, CT: Computerized Tomography

non-cancer (including arterial and brain premature aging) effects in our patients and in ourselves as exposed population. In particular, the interventional cardiology community should play a proactive role in collecting new evidence. In the USA, the Multispecialty Occupational Health Group network triggered a cohort mortality study comparing cancer and other serious disease outcomes (including cardiovascular disease) in 44,000 physicians performing fluoroscopically guided procedures (including interventional cardiologists, cardiac electrophysiologists, radiologists, neuroradiologists and others) ${ }^{32}$. In Italy, the Healthy Cath Lab study is organized by the Italian National Research Council-Institute of Clinical Physiology with endorsement by the Italian Society of Invasive Cardiology. The Italian study population will involve 500 exposed interventional cardiologists and staff (technicians and nurses) evaluated by a molecular epidemiology approach to assess „early warning signs" of brain and vascular aging.

For the industry, there is growing interest in new textile materials for better and more ergonomic shielding for patients and doctors, also based on novel alloys and nano-technology. Novel solutions for real-time dosimetry for doctors and exact organ dose assessment for patients are being actively investigated and have great potential to become game-changers in the device market, as is happening in electrophysiology with new techniques for near-zero exposure based on non-fluoroscopic navigation in electrophysiology.

Finally, the patient will benefit from these innovations, since in the end radiation doses will drop and the benefit will remain the same, making the cardiac catheterization lab a safer place. Radioprotection will mainly benefit the invasive cardiologist, who will realize that the strict application of very basic principles of radioprotection - time, shielding and distance principles - will make his/her life healthier and longer. The amount of radiation exposure decreases with the shorter time of use of radiation and with the greater distance from the radiation source and the patient. As a rule, by doubling the distance, one reduces the exposure by a factor of 4. Several items can aid in shielding, which can reduce exposure by a factor of 10: leaded aprons of course, but also special glasses to protect from cataract formation, thyroid collars, and ceiling-mounted overhead radiation shields. In many catheterization laboratories, these resources do not exist -- or are not employed routinely ${ }^{33}$.

\section{Conclusions}

The advent of radioprotection culture in the cardiac catheterization lab is a unique opportunity for today's generation of professionals, who have the responsibility to change time-honored radiation-insensitive practices that increase the risk to patients and to us without any benefit (Table 3). The key messages are simple:

1. Attention to radioprotection is one aspect - and not the least important - of good practice of interventional cardiology.

2. Protecting the patient from an unjustified or unoptimized dose is the best way to protect yourself and your staff.

3. Before the exam, both you and the patient should know the expected delivered dose (which is directly proportional to the long-term risk).

4. During the exam, make every effort to keep the dose as low as possible.

5. After the exam, write the dose down in the records. You and your patient need to know it, because short-term (weeks or months) deterministic (skin ulcers) and long-term (years or decades) stochastic (cancer) risk depend on it.

And finally: a smart interventional cardiologist cannot be afraid of radiation, but must be very afraid of radiation unawareness ${ }^{1}$. 


\section{References}

1. Picano E, Vañó E, Rehani MM, Cuocolo A, Mont L, Bodi V, Bar O, Maccia C, Pierard L, Sicari R, Plein S, Mahrholdt H, Lancellotti P, Knuuti J, Heidbuchel H, Di Mario C, Badano LP. The appropriate and justified use of medical radiation in cardiovascular imaging: a position document of the ESC Associations of Cardiovascular Imaging, Percutaneous Cardiovascular Interventions and Electrophysiology. Eur Heart J 2014;35:665-672.

2. Vañó E, González L, Guibelalde E, Fernández JM, Ten JI. Radiation exposure to medical staff in interventional and cardiac radiology. Br J Radiol 1998;71:954-960.

3. Venneri L, Rossi F, Botto N, Andreassi MG, Salcone N, Emad A Lazzeri M, Gori C, Vano E, Picano E. Cancer risk from professiona exposure in staff working in cardiac catheterization laboratory: insights from the National Research Council's Biological Effects of Ionizing Radiation VII Report. Am Heart J 2009;157:118-124.

4. Correia MJ, Hellies A, Andreassi MG, Ghelarducci B, Picano E. Lack of radiological awareness among physicians working in a tertiary-care cardiological centre. Int J Cardiol 2005;103:307-311.

5. Kim C, Vasaiwala S, Haque F, Pratap K, Vidovich MI. Radiation safety among cardiology fellows. Am J Cardiol 2010;106:125-128.

6. Hirshfeld JW Jr, Balter S, Brinker JA. et al. American College of Cardiology Foundation; American Heart Association/; HRS; SCAI American College of Physicians Task Force on Clinical Competence and Training (2005). ACCF/AHA/HRS/SCAl clinical competence statement on physician knowledge to optimize patient safety and image quality in fluoroscopically guided invasive cardiovascular procedures: a report of the American College of Cardiology Foundation/American Heart Association/ American College of Physicians Task Force on Clinical Competence and Training. Circulation 111:511-532.

7. Picano E, Vañó E. Radiation exposure as an occupational hazard. Eurolntervention 2012;8:649-653.

8. Heidbuchel H, Wittkampf F, Vano E, Ernst S, Schilling R, Picano $E$, Mont L. Practical ways to reduce radiation dose for patients and staff during device implantations and electrophysiological procedures. EHRA Position Paper. Europace 2013. doi:10.1093/ europace/eut409.

9. BEIR VII Health Risks from Exposure to Low Levels of Ionizing Radiation, Phase 2. http://www.nap.edu/openbook. php?isbn=030909156X. Retrieved: February 17th, 2014

10. Report of the United Nations Scientific Committee on the Effects of Atomic Radiation 2010. Fifty-seven session: Summary of Low dose Radiation Effects on Health. Wien, May 2011. http://www. unscear.org/docs/reports/2010/UNSCEAR_2010_Report_M.pdf

11. Frazier TH, Richardson JB, Fabré VC, Callen JP. Fluoroscopyinduced chronic radiation skin injury: a disease perhaps often overlooked. Arch Dermatol 2007;143:637-640.

12. Rehani MM, Srimahachota S. Skin injuries in interventional procedures. Radiat Prot Dosimetry 2011;147:8-12.

13. Stewart FA, Akleyev AV, Hauer-Jensen M, Hendry JH, Kleiman NJ, Macvittie TJ, Aleman BM, Edgar AB, Mabuchi K, Muirhead $\mathrm{CR}$, Shore RE, Wallace WH. ICRP statement on tissue reactions and early and late effects of radiation in normal tissues and organs - threshold doses for tissue reactions in a radiation protection context. Ann ICRP 2012;41:1-322. Authors on behalf of ICRP, doi:10.1016/j.icrp.2012.02.001.

14. Rehani MM, Vano E, Ciraj-Bielac O, Kleiman NJ. Radiation and cataract. Radiat Prot Dosimetry 2011;147:300-304.

15. Radiation Protection 125. Low dose ionizing radiation and cancer risk. Luxembourg, 2001 http://ec.europa.eu/energy/nuclear/radiation_protection/doc/publication/125.pdf
16. Bernardi G, Padovani R, Morocutti G, Vañó E, Malisan MR, Rinuncini M, Spedicato L, Fioretti PM. Clinical and technical determinants of the complexity of percutaneous transluminal coronary angioplasty procedures: analysis in relation to radiation exposure parameters. Catheter Cardiovasc Interv 2000;51:1-9.

17. Vañó E. Radiation exposure to cardiologists: how it could be reduced. Heart 2003;89:1123-1124.

18. Rehani M, Ciraj Bjekac O, Vañó E, Miller DL, Walsh S, Giordano $\mathrm{BD}$, Perslinden J. Radiological protection in fluoroscopically guided procedures performed outside the imaging department. ICRP Publication 117. Ann ICRP 2010;40:1-102.

19. Vaño E, Gonzalez L, Fernandez JM, Alfonso F, Macaya C. Occupational radiation doses in interventional cardiology: a 15-year follow-up. Br J Radiol 2006;79:383-388.

20. Andreassi MG, Cioppa A, Botto N, Joksic G, Manfredi S, Federici C, Ostojic M, Rubino P, Picano E. Somatic DNA damage in interventional cardiologists: a case-control study. FASEB J 2005;19:998-999.

21. Andreassi MG, Foffa I, Manfredi S, Botto N, Cioppa A, Picano E. Genetic polymorphisms in XRCC1, OGG1, APE1 and XRCC3 DNA repair genes, ionizing radiation exposure and chromosomal DNA damage in interventional cardiologists. Mutat Res 2009;666:57-63.

22. Andreassi MG, Cioppa A, Manfredi S, Neri MG, Foffa I, Picano E. $\mathrm{N}$-acetyl cysteine reduces chromosomal DNA damage in circulating lymphocytes during cardiac catheterization procedures: a pilot study. Int J Cardiol 2012;161:93-96.

23. Kovoor P, Ricciardello M, Collins L, Uther JB, Ross DL. Risk to patients from radiation associated with radiofrequency ablation for supraventricular tachycardia. Circulation 1998;98:1534-1540.

24. Picano E. Informed consent and communication of risk from radiological and nuclear medicine examinations: how to escape from a communication inferno. Education and debate. BMJ 2004;329:849-851.

25. Terranova G, Ferro M, Carpeggiani C, Recchia V, Braga L, Semelka RC, Picano E. Low quality and lack of clarity of current informed consent forms in cardiology: how to improve them. JACC Cardiovasc Imaging 2012;5:649-655.

26. Picano $E$, Vañó $E$. The radiation issue in cardiology: the time for action is now. Cardiovasc Ultrasound 2011;9:35.

27. Borghini A, Gianicolo EA, Picano E, Andreassi MG. Ionizing radiation and atherosclerosis: current knowledge and future challenges. Atherosclerosis 2013;230:40-47.

28. Picano E. Sustainability of medical imaging. Review. Brit Med J 2004; 328:578-580.

29. The Creative Destruction of Medicine: How the Digital Revolution Will Create Better Health Care by Eric Topol. Basic Books, New York, 2012.

30. Conti CR. Radiation awareness. An appeal is made for including radiation exposure in a patient's medical records. Eur Heart J 2014; 35:600-601.

31. Abu Hazeem AA, Dori Y, Whitehead KK, Harris MA, Fogel MA, Gillespie MJ, Rome JJ, Glatz AC. X-ray magnetic resonance fusion modality may reduce radiation exposure and contrast dose in diagnostic cardiac catheterization of congenital heart disease. Catheter Cardiovasc Interv 2014 Mar 12. doi: 10.1002/ccd.25473

32. Linet MS, Kim KP, Miller DL, Kleinerman RA, Simon SL, Berrington de Gonzalez A. Historical review of occupational exposures and cancer risks in medical radiation workers. Radiat Res 2010;174:793-808.

33. Roguin A. CardioPulse Articles . Radiation in cardiology: can't live without it! Eur Heart J 2014;35:599-604. 